\title{
Ueber Flammenschutzmittel;
}

\section{von A. Patera.}

Ueber diesen wichtigen Gegenstand ist unter dem obigen Titel vom Bergrath Patera in Wien eine kleine Schrift erschienen, welche die gröfste Aufmerksamkeit verdient. Denn so grofsartig die Anstalten und Mittel sind, die angewandt werden, um dem bereits ausgebrochenen Feuer Einhalt zu thun, so wenig allgemeine Berücksichtigung haben bis jetzt die Bestrebungen gefunden, solche Unglïcksfälle, durch die so enorme Verluste an Hab und Gut und Menschenleben herbeigeführt werden, $z u$ verhüten. Das Bedürfnifs sie zu verhüten liegt zunåchst nahe bei der leichten Entzündlichkeit der Theaterdecorationen und der meisten Frauen-Kleiderstoffe. Patera giebt an, dafs man die Anzahl der jährlich in England durch brennende Kleider Verunglückten auf mehr als 400 schätzt, und dars in Wien nach einem fünfjährigen Durchschnitt jäirlich 21 Personen auf diese Weise durch Verbrennung verunglücken. Er erinnert ferner an den Brand der Kirche zu St. Jago im Jahre 1863, bei welchem in einer Viertelstunde mehr als 2000 Frauen ihren Tod fanden, indem eine Gasflamme einen Vorhang in Brand setzte und das Feuer sich durch die Kleider der Frauen weiter verbreitete. Oben an in Bezug auf Feuergefährlichkeit stehen ferner die Theater. Beim Brande des Theaters von Saragossa im Jahre 1787 verloren 600 Personen das Leben; bei dem Brande des Theaters in Quebeck im Jahre 1846 kamen über 500 Personen um. Im Jahre 1868 fingen in Turin die Kleider einer Tänzerin Feuer, das sich auf die anderen Tänzerinnen fortplanzte und wodurch zuletzt das ganze Theater in Asche gelegt wurde. Mit Berücksichtigung der in neuester Zeit erfolgten Brände sind in den letzten 109 Jahren 136 Theater vollständig' abge- 
brannt, von welchen 51 auf die letzten 10 . Jahre fallen. Es ist also klar, dafs es eine Sache von grofser Wichtigkeit ist, Mittel aufzufinden, durch welche die Entzündlichkeit leicht feuerfangender Stofle verzögert und vermindert werden kann. Nachdem der Verfasser den Verbrennungsprocefs bei verschiedenen Stoffen (Leinen, Baumwolle, Holz) klar und gründlich erörtert kat, unterwirft er die bereits in Vorschlag gebrachten, die Entzündlichkeit verzögernden und die Verbrennung mit Flanme verhindernden Mittel einer nöheren Betrachtung. $\mathrm{Zu}$ den schon längst vorgeschlagenen und fast ganz vergessenen gehört das von $F$ u $\mathrm{ch}$ s empfohlene Wasserglas, mit dessen mit Kreide vermischter Lösung bei dem Neubau des 1823 abgebrannten Hoftheaters in München alles Holzwerk angestrichen wurde und das der Verfasser selbst noch jetzt zu den besten Schutzmitteln für Holz rechnet. Dann erwähnt er des von Versmann und Oppenheim vorgeschlagenen wolframsauren Natrons als eines sehr dem Zweck entsprechenden Mittels, dem aber bei einer massenhaften Anwendung die zu grofse hostbarkeit entgegenstehe. Auch das von denselben vorgeschlagene schwefelsaure Ammoniak leiste gute Dienste, erfordere aber gewisse Vorsichten und sei daher in vielen Fällen unanwendbar. Nachdem er noch versehiedene undere, neuerlich empfohlene Mittel genannt und ihre Uebelstände bei der Anwendung hervorgehoben hat (die Alaune, Vitriole, Borax, Bittersalz, Salmiak u. s. w.), komint er zu den von ihm selbst aufgefundenen und erprobten Flammenschutzmitteln, die auch den übrigen Anforderungen : wohlfeil und leicht zugänglich zu sein, in möglichst verdünnter Lösung zu wirken, die Stoffe nicht steif und schwer zu machen, die Farben nicht zu verderben, nicht riechend, nicht ätzend, nicht giftig zu sein, vollkommen entsprechen.

Nach seinen vielfachen belehrenden Versuchen, die ausführlich beschrieben sind, hält Pale ra ein Gemenge von 
Borax und Bittersalz für ein Flanmenschutzmittel, welches dem wolfransauren Natron mindestens gleich $\mathrm{zu}$ stellen und dabei überall wohlfeil zu haben sei. Seine Wirkung beruht auf der Bildung der in kaltem und heifsem Wasser unlöslichen borsauren Magnesia, welche die Fäden des Gewebes dicht umhüllt, und, indem sie so die Entwickelung der brennbaren Gase sehr erschwert, das Umsichgreifen der Flamme verhindert. Das Mischungsverhältnifs der Salze ist : 4 Theile Borax und 3 Theile Bittersalz. Die Salze werden erst kurz vor dem Gebrauch gemengt, weil sich sonst zu früh borsaure Magnesia bildet und ungelöst bleibt. 7 Loth des Salzgemenges werden in 20 bis 30 Loth warmen Wassers gelöst und in diese Lösung der zu imprägnirende Stoff trocken eingetaucht; er wird dann ausgerungen und getrocknet oder nöthigenfalls gebügelt.

Ein zweiles, nach seiner Versicherung vortreffliches Schutzmittel fand er in einem Gemenge von schwefelsaurem Ammoniak und Gyps, in verschiedenen Verhältnissen, je nachdem es für feinere oder gröbere Stoffe dienen soll. - Beide Salzgemenge eignen sich für alle feineren und gröberen Stoffe, für Crepe, Tüll, Mousselin, Packleinwand, Holz und Stricke. In Betreff der Einzelheiten bei der Imprägnation verschiedener Stoffe mit den beiden Salzgemengen oder mit Wasserglas vurweisen wir auf die kleine Schrift. 